\title{
Vapor-liquid equilibrium of mixtures containing formaldehyde, water, and butynediol
}

\author{
Jürgen Berje ${ }^{a}$, Jens Baldamus ${ }^{b}$, Jakob Burger ${ }^{a,}{ }^{*}$, Hans Hasse ${ }^{a}$ \\ a Laboratory of Engineering Thermodynamics, University of Kaiserslautern, 67663, Kaiserslautern, Germany \\ ${ }^{\mathrm{b}}$ BASF SE, 67056, Ludwigshafen, Germany
}

\section{A R T I C L E I N F O}

\section{Article history:}

Received 29 November 2018

Received in revised form

25 February 2019

Accepted 28 February 2019

Available online 5 March 2019

\section{Keywords:}

Formaldehyde

Butynediol

VLE

Model

Residue curves

\begin{abstract}
A B S T R A C T
Measurements of the vapor-liquid equilibrium in the system formaldehyde + water + butynediol were performed at $393 \mathrm{~K}$ and $413 \mathrm{~K}$ for overall formaldehyde mass fractions between $0.1 \mathrm{~g} \mathrm{~g}^{-1}$ and $0.2 \mathrm{~g} \mathrm{~g}^{-1}$ and overall butynediol mass fractions between $0.05 \mathrm{~g} \mathrm{~g}^{-1}$ and $0.35 \mathrm{~g} \mathrm{~g}^{-1}$. The studied system is a complex reactive multicomponent mixture as formaldehyde reacts both with formaldehyde and butynediol. A predictive physico-chemical model of the vapor-liquid equilibrium from the literature [1] is validated by the experiments of the present work. Residue curves are calculated to illustrate the distillation behavior of the studied system.
\end{abstract}

๑) 2019 Elsevier B.V. All rights reserved.

\section{Introduction}

Butynediol is an important intermediate in the $C 4$ value added chain. A technical route for the synthesis of butynediol is the reaction of acetylene with aqueous formaldehyde solution [2-4] yielding a mixture of butynediol, water, and unconverted formaldehyde. For the purification of butynediol, formaldehyde has to be removed from this mixture, which is usually done by distillation. Developing a model of the vapor-liquid equilibrium in the system formaldehyde + water + butynediol is challenging as formaldehyde forms oligomers both with water [5] and with butynediol [1].

Vapor-liquid equilibrium models for mixtures containing formaldehyde, water, and methanol have been presented in many studies [6-20]. Experimental data and an activity-based model of the chemical equilibrium in liquid mixtures of formaldehyde, water, and butynediol have only very recently become available [1]. The model takes all conceivable oligomerization reactions into account and also implicitly contains a model of the physical equilibrium between liquid and vapor phase. The model is predictive since it does not contain any parameters fitted to vapor-liquid equilibrium data with formaldehyde and butynediol.

\footnotetext{
* Corresponding author. Technical University of Munich, Campus Straubing for Biotechnology and Sustainability, Chair of Chemical Process Engineering, 94315, Straubing, Germany.

E-mail address: burger@tum.de (J. Burger).
}

To the authors' knowledge, no experimental vapor-liquid equilibrium data for systems containing formaldehyde and butynediol have been published to date. Therefore, the vapor-liquid equilibrium in the system formaldehyde + water + butynediol was studied experimentally in this work in a special type of thin-film evaporator which is known to be suited for determining vaporliquid equilibria of reactive formaldehyde-containing mixtures $[7,8,11-15,18,19]$. The data are used for the validation of the predictive model mentioned above.

In the last part of this work, residue curves for the overall ternary system formaldehyde + water + butynediol are presented. These curves allow conceptual feasibility studies for distillation processes involving formaldehyde, water, and butynediol.

\section{Vapor-liquid equilibrium model}

Fig. 1 shows a scheme of the vapor-liquid equilibrium model in the system formaldehyde + water + butynediol including the chemical reactions. The reactions occur at any $\mathrm{pH}$ value without requiring catalysts. Formaldehyde (FA) and water $(\mathrm{W})$ yield methylene glycol $\left(\mathrm{MG}_{1}\right)$ :

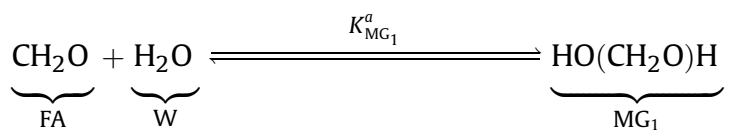




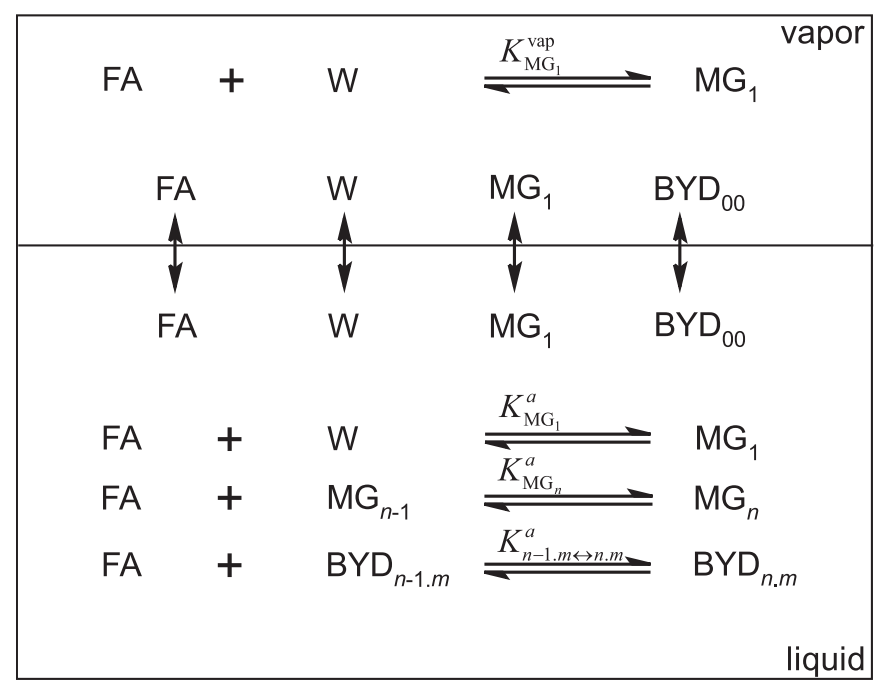

Fig. 1. Schematic of the reactive vapor-liquid equilibrium model considering the chemical reactions in the system formaldehyde (FA) + water $(\mathrm{W})+$ butynediol $\left(B_{0.0}\right)$. Poly(oxymethylene) glycols $\left(\mathrm{MG}_{n}\right)$ and poly(oxymethylene) hemiformals $\left(\mathrm{BYD}_{n . m}\right)$ are formed by addition reactions. See text for explanation of the reactions.

Poly(oxymethylene) glycols $\left(\mathrm{MG}_{n}\right)$ are formed in chain propagation reactions: $p_{i}^{\mathrm{s}} \cdot x_{i} \cdot \gamma_{i}=p \cdot y_{i} \quad i=\mathrm{FA}, \mathrm{W}, \mathrm{MG}_{1}, \mathrm{BYD}_{0.0}$

where $p_{i}^{\mathrm{s}}$ is the vapor pressure of component $i, x_{i}$ the true mole fraction of component $i$ in the liquid phase, $\gamma_{i}$ the activity coefficient of component $i$ in the liquid phase, $p$ the pressure, and $y_{i}$ the true mole fraction of component $i$ in the vapor phase. Ideal vapor phase is assumed and the Poynting correction is neglected. As activity-based chemical equilibrium constants are used for describing the liquid phase reactions, the model is thermodynamically consistent. Reaction (I) occurs in both phases. The corresponding chemical equilibrium constants are connected by Equation (1) following Maurer [6], cf [1]. The calculation of activity coefficients and pure component vapor pressures were also taken from Ref. [1].Two types of concentration measures are used to characterize the composition of a phase: true concentrations $\left(x_{i}, y_{i}\right)$ and overall concentrations $\left(\tilde{x}_{i}, \tilde{y}_{i}\right)$. The overall concentrations consider only the components formaldehyde, water, and butynediol, i.e. the concentrations of these components if all formaldehyde chains would decompose. In the model and the calculations of this work, true concentrations are used. For the presentation of the experimental data and the comparison with the model predictions overall concentrations are used. Mass fractions are used for the latter rather than mole fractions. This facilitates the presentation of the results of the studied mixtures in which butynediol has a much higher molar mass than formaldehyde and water. To differentiate mass fractions in the symbol notation, the superscript (m) is used,
$\underbrace{\mathrm{CH}_{2} \mathrm{O}}_{\text {FA }}+\underbrace{\mathrm{HO}\left(\mathrm{CH}_{2} \mathrm{O}\right)_{n-1} \mathrm{H}}_{\mathrm{MG}_{n-1}} \rightleftharpoons \underbrace{a}_{\mathrm{MG} n} \rightleftharpoons \underbrace{\mathrm{HO}\left(\mathrm{CH}_{2} \mathrm{O}\right)_{n} \mathrm{H}}_{\mathrm{MG}_{n}} \quad n>1$

e.g. $\tilde{x}_{\mathrm{FA}}^{(\mathrm{m})}$, in contrast to mole fractions where the superscript is omitted, e.g. $\tilde{x}_{\mathrm{FA}}$.All calculations in this work were performed with formals (BYD $n . m$ ) according to
In this manner butynediol is $\mathrm{BYD}_{0.0}$. Due to symmetry, $\mathrm{BYD}_{n . m}$ and $\mathrm{BYD}_{m . n}$ are the same compounds and do not have to be considered separately in the equilibrium model. Reaction (I) takes place both in the vapor and in the liquid phase. Following Maurer [6], it is assumed that no poly(oxymethylene) glycols with $n>1$ are present in the vapor phase, due to their low vapor pressures. Adapting that argument, only monomeric butynediol $\left(\mathrm{BYD}_{0.0}\right)$ is considered here in the vapor phase. As a consequence, reactions of formaldehyde with butynediol are only considered in the liquid phase.

In the present work, activity-based chemical equilibrium constants are used for the calculation of the species distribution in the liquid phase. The equilibrium constants were taken from Ref. [1]. The phase equilibrium of the components present in both phases is modeled using the extended Raoult's Law the software gPROMS (version: 3.6, Process Systems Enterprise Limited, London, UK) taking into account poly(oxymethylene) glycols up to $n=10$ and poly(oxymethylene) hemiformals up to $n+$ $m=10$.

\section{Experimental}

\subsection{Experimental plan}

To remove formaldehyde from aqueous, alcoholic solutions, high temperatures are favorable [16]. However, at temperatures above $423 \mathrm{~K}$ decomposition of butynediol can occur [21]. The goal of the present work is to validate a model that is used in the workup after the BYD reactor. To remove formaldehyde from aqueous, alcoholic solutions, high temperatures are favorable [16]. Preliminary evaluations with the model predicted that at temperatures 
below $390 \mathrm{~K}$, the separation of formaldehyde and BYD in the VLE becomes unsatisfactory. Therefore, the vapor-liquid equilibrium measurements in the present work were carried out at $393 \mathrm{~K}$ and $413 \mathrm{~K}$ in a concentration range which is interesting for the present applications: $\tilde{x}_{\mathrm{FA}}^{(\mathrm{m})}$ ranging from $0.1 \mathrm{~g} \mathrm{~g}^{-1}$ to $0.2 \mathrm{~g} \mathrm{~g}^{-1}$ and $\tilde{x}_{\mathrm{BYD}}^{(\mathrm{m})}$ from $0.05 \mathrm{~g} \mathrm{~g}^{-1}$ to $0.35 \mathrm{~g} \mathrm{~g}^{-1}$.

\subsection{Experimental setup}

For the vapor-liquid equilibrium measurements a thin-film evaporator was used which already has been successfully used for the measurements of vapor-liquid equilibria in formaldehyde containing systems $[11-14,18]$. Since apparatus and measurement procedure are already well described (see also [7,8]), just a short outline is given here.

The apparatus consists of a rotating coil which spreads a preheated, equilibrated liquid feed on the inner surface of a stainless steel tube surrounded by a heating jacket. After partial evaporation and equilibration, vapor and liquid phase are separated, cooled down and collected into glass vessels. The temperature is measured with a PT100 thermometer in a siphon for the liquid phase. Nitrogen back pressure is used to regulate the pressure both in the apparatus and the feed vessel. The accuracy of the temperature measurement is $\pm 0.05 \mathrm{~K}$, the accuracy of the pressure measurement is $\pm 0.1 \mathrm{kPa}$.

To keep the residence time for equilibration high and the disturbance of the chemical equilibrium in the liquid phase low, the following experimental parameters were chosen: feed flow rate below $30 \mathrm{~mL} \mathrm{~h}^{-1}$ (cf. Hasse [7]), rotation rate of the coil $30 \mathrm{rpm}$, volume ratio of condensed vapor phase to liquid phase about 1:8. The estimated resulting residence time is about $2 \mathrm{~min}$. It is known [8] for the system formaldehyde + water that this residence time is sufficient to reach chemical equilibrium in the vapor phase at the temperatures chosen here. Since the amount of butynediol in the vapor phase is negligible (cf. results), the considerations also hold for the system with butynediol.

\subsection{Chemicals and sample preparation}

Table 1 lists the commercially obtained chemicals for the experiments. Aqueous formaldehyde stock solutions were prepared by dissolving paraformaldehyde in ultrapure water at elevated temperature. A detailed procedure is described by Hasse [7]. The overall formaldehyde mass fraction in the stock solutions was determined titrimetrically by the $\mathrm{Na}_{2} \mathrm{SO}_{3}$ method [5]. The ultrapure water was produced in a Milli-Q integral water purification system from MerckMillipore, Darmstadt, Germany. Butynediol was purified by recrystallization with diethyl ether from ethyl acetate as described by Pyatnitsyna et al. [22].

Ternary mixtures of formaldehyde, water, and butynediol were prepared gravimetrically from an aqueous formaldehyde stock solution and recrystallized butynediol using a precision balance (Mettler Toledo XS603S, Greifensee, Switzerland). For chemical equilibration the ternary mixtures are stored in the feed vessel of the thin-film evaporator for at least $2 \mathrm{~h}$ at measurement temperature.
Table 2

Settings of the gas chromatograph.

\begin{tabular}{ll}
\hline Injection volume & $0.2 \mathrm{~L}$ \\
\hline Inlet temperature & $250{ }^{\circ} \mathrm{C}$ \\
Helium flow rate & $0.9 \mathrm{~mL} \mathrm{~min}^{-1}$ \\
Split ratio & $30: 1$ \\
Temperature program & 0.5 min at $100^{\circ} \mathrm{C}$ \\
& $20^{\circ} \mathrm{C} \mathrm{min}-1$ up to $250{ }^{\circ} \mathrm{C}$ \\
Detector temperature & $4 \mathrm{~min}^{\circ} 250^{\circ} \mathrm{C}$ \\
Reference flow & $250^{\circ} \mathrm{C}$ \\
Column + makeup flow & $20 \mathrm{~mL} \mathrm{~min}^{-1}$ \\
\hline
\end{tabular}

\subsection{Sample analysis}

The overall formaldehyde mass fraction was determined titrimetrically by the $\mathrm{Na}_{2} \mathrm{SO}_{3}$ method [5]. The overall mass fraction of butynediol was determined by gas chromatography (HP 6890, Hewlett-Packard, Palo Alto, CA, USA) with a Rtx ${ }^{\circledR}$-Wax column (cat.no. 12454, Restek, Bellefonte, PA, USA) and a thermal conductivity detector. $200 \mu \mathrm{L}$ of 1,4-Butanediol (99\%, Acros Organics) were used as internal standard with $1 \mathrm{~mL}$ of the sample to be analyzed. The settings are reported in Table 2.

The gas chromatograph was calibrated with mixtures of known composition. Mixtures of water + butynediol and formaldehyde + water + butynediol were used for the calibration. The preparation of these mixtures was performed as described above.

The overall butynediol concentration was determined ten times for each sample. The mean standard deviation of the determined mean value in the liquid phase is $\pm 0.0003 \mathrm{~g} \mathrm{~g}^{-1}$. The relative accuracy of the butynediol concentration is $2 \%$. The determination of the overall formaldehyde concentration was carried out at least three times for each sample. The standard deviation of the determined formaldehyde mass fraction is about $\pm 0.0001 \mathrm{~g} \mathrm{~g}^{-1}$. The relative accuracy of the formaldehyde concentration is $3 \%$. The water content was determined from the summation equation.

\section{Results and discussion}

In general, few butynediol was found in the vapor phase due to its low vapor pressure. In most experiments, the experimental mass fraction of butynediol in the vapor phase just reaches the detection limit of ca. $0.0010 \mathrm{~g} \mathrm{~g}^{-1}$, in some experiments the amount of butynediol is not measurable. The results of the vapor-liquid equilibrium measurements are given in Table 3. The experiments in which butynediol could not be detected in the vapor phase are flagged with an asterisk. Table 3 also shows the predictions of the model described above. They were obtained by specifying the temperature and the overall liquid composition.

Even though the new experimental data was not used in the model development, a comparison of the model predictions with the new data show excellent agreement. The deviations of the overall mass fraction of formaldehyde in the vapor phase and the pressure are $3.6 \%$ and $0.6 \%$, respectively. Since butynediol was detected merely at concentrations around the detection limit, the average deviation of the mass fraction in the vapor phase is quite

Table 1

Provenance of chemicals.

\begin{tabular}{|c|c|c|c|c|}
\hline Chemical & IUPAC name & CAS-No. & Manufacturer & Manufacturer specification \\
\hline Paraformaldehyde & Polyoxymethylene & $30525-89-4$ & Merck & $\begin{array}{l}\geq 0.95 \mathrm{~g} \mathrm{~g}^{-1} \text { paraformaldehyde } \\
\leq 0.05 \mathrm{~g} \mathrm{~g}^{-1} \text { water }\end{array}$ \\
\hline Butynediol & 2-Butyne-1,4-diol & $110-65-6$ & Acros Organics & $\geq 0.99 \mathrm{~g} \mathrm{~g}^{-1}$ \\
\hline
\end{tabular}


Table 3

Vapor-liquid equilibrium in the system formaldehyde + water + butynediol. Comparison of experimental data from the present work with model predictions.

\begin{tabular}{|c|c|c|c|c|c|c|c|c|c|c|c|}
\hline$T / \mathrm{K}^{\mathrm{a}}$ & $\tilde{x}_{\mathrm{FA}}^{(\mathrm{m}), \exp } / \mathrm{g} \mathrm{g}^{-1 \mathrm{a}}$ & $\tilde{x}_{\mathrm{BYD}}^{(\mathrm{m}), \exp } / \mathrm{g} \mathrm{g}^{-1 \mathrm{a}}$ & $\tilde{y}_{\mathrm{FA}}^{(\mathrm{m}) \exp } / \mathrm{g} \mathrm{g}^{-1 \mathrm{a}}$ & $\tilde{y}_{\mathrm{FA}}^{(\mathrm{m}), \mathrm{mod}} / \mathrm{g} \mathrm{g}^{-1}$ & $\Delta \tilde{y}_{\mathrm{FA}} / \%$ & $\tilde{y}_{\mathrm{BYD}}^{(\mathrm{m}), \exp } / \mathrm{g} \mathrm{g}^{-1 \mathrm{a}}$ & $\tilde{y}_{\mathrm{BYD}}^{(\mathrm{m}), \mathrm{mod}} / \mathrm{g} \mathrm{g}^{-1}$ & $\Delta \tilde{y}_{\mathrm{BYD}} / \%$ & $p^{\exp } / \mathrm{kPa}^{\mathrm{a}}$ & $p^{\mathrm{mod}} / \mathrm{kPa}$ & $\Delta p / \%$ \\
\hline 393.4 & 0.0102 & 0.3418 & 0.0131 & 0.0125 & 4.58 & 0.0019 & 0.0018 & 5.26 & 184.4 & 186.8 & -1.29 \\
\hline 393.1 & 0.0129 & 0.2212 & 0.0181 & 0.0185 & -2.02 & 0.0010 & 0.0012 & -20.00 & 189.7 & 190.5 & -0.41 \\
\hline 393.2 & 0.0195 & 0.1068 & 0.0314 & 0.0336 & -6.89 & $0^{\mathrm{b}}$ & 0.0006 & $0^{\mathrm{b}}$ & 198.0 & 196.5 & 0.76 \\
\hline 393.1 & 0.0202 & 0.2167 & 0.0295 & 0.0289 & 2.03 & 0.0010 & 0.0011 & -10.00 & 190.9 & 192.0 & -0.56 \\
\hline 393.3 & 0.0301 & 0.3456 & 0.0379 & 0.0361 & 4.75 & 0.0015 & 0.0016 & -6.67 & 184.8 & 187.3 & -1.38 \\
\hline 393.2 & 0.0477 & 0.2278 & 0.0687 & 0.0651 & 5.29 & $0^{\mathrm{b}}$ & 0.0010 & $0^{\mathrm{b}}$ & 194.0 & 193.7 & 0.17 \\
\hline 393.1 & 0.0483 & 0.0504 & 0.0840 & 0.0872 & -3.81 & $0^{\mathrm{b}}$ & 0.0002 & $0^{\mathrm{b}}$ & 202.9 & 202.4 & 0.27 \\
\hline 392.8 & 0.0489 & 0.2228 & 0.0658 & 0.0667 & -1.37 & $0^{\mathrm{b}}$ & 0.0009 & $0^{\mathrm{b}}$ & 191.6 & 191.7 & -0.05 \\
\hline 393.2 & 0.0494 & 0.0535 & 0.0870 & 0.0885 & -1.76 & $0^{\mathrm{b}}$ & 0.0002 & $0^{\mathrm{b}}$ & 203.5 & 203.0 & 0.27 \\
\hline 393.2 & 0.0626 & 0.1048 & 0.0959 & 0.1000 & -4.28 & $0^{\mathrm{b}}$ & 0.0004 & $0^{\mathrm{b}}$ & 200.3 & 201.1 & -0.38 \\
\hline 393.2 & 0.0932 & 0.2131 & 0.1253 & 0.1225 & 2.23 & $0^{\mathrm{b}}$ & 0.0007 & $0^{\mathrm{b}}$ & 198.5 & 198.0 & 0.23 \\
\hline 393.2 & 0.0959 & 0.1125 & 0.1390 & 0.1426 & -2.59 & $0^{\mathrm{b}}$ & 0.0003 & $0^{\mathrm{b}}$ & 203.4 & 203.7 & -0.14 \\
\hline 393.2 & 0.1193 & 0.1389 & 0.1670 & 0.1651 & 1.14 & $0^{\mathrm{b}}$ & 0.0004 & $0^{\mathrm{b}}$ & 204.5 & 204.8 & -0.13 \\
\hline 413.2 & 0.0092 & 0.2085 & 0.0172 & 0.0177 & -3.11 & 0.0030 & 0.0021 & 30.00 & 350.7 & 350.2 & 0.13 \\
\hline 413.3 & 0.0170 & 0.1105 & 0.0337 & 0.0375 & -11.28 & 0.0013 & 0.0012 & 7.69 & 362.4 & 359.9 & 0.69 \\
\hline 413.3 & 0.0191 & 0.3247 & 0.0320 & 0.0314 & 1.98 & 0.0034 & 0.0029 & 14.71 & 340.8 & 343.0 & -0.64 \\
\hline 413.3 & 0.0442 & 0.1814 & 0.0780 & 0.0831 & -6.54 & 0.0014 & 0.0015 & -7.14 & 371.1 & 361.4 & 2.60 \\
\hline 413.2 & 0.0452 & 0.1063 & 0.0957 & 0.0943 & 1.43 & $0^{\mathrm{b}}$ & 0.0009 & $0^{\mathrm{b}}$ & 372.4 & 368.6 & 1.03 \\
\hline 413.2 & 0.0456 & 0.2866 & 0.0786 & 0.0754 & 4.07 & 0.0024 & 0.0022 & 8.33 & 352.3 & 352.0 & 0.07 \\
\hline 413.2 & 0.0465 & 0.0532 & 0.0993 & 0.1050 & -5.70 & $0^{\mathrm{b}}$ & 0.0005 & $0^{\mathrm{b}}$ & 377.8 & 374.3 & 0.93 \\
\hline 413.3 & 0.0803 & 0.1905 & 0.1423 & 0.1400 & 1.62 & 0.0015 & 0.0012 & 20.00 & 371.8 & 369.4 & 0.64 \\
\hline 413.2 & 0.0905 & 0.0949 & 0.1673 & 0.1732 & -3.53 & 0.0011 & 0.0005 & 54.55 & 383.4 & 382.3 & 0.29 \\
\hline 413.2 & 0.1675 & 0.1762 & 0.2610 & 0.2559 & 1.95 & 0.0011 & 0.0006 & 45.45 & 393.1 & 389.6 & 0.89 \\
\hline
\end{tabular}

${ }^{\mathrm{a}} u(T)=0.05 \mathrm{~K}, u\left(p^{\exp }\right)=0.1 \mathrm{kPa}, u\left(\tilde{x}_{\mathrm{FA}}^{(\mathrm{m}), \exp }\right)=0.03 \tilde{x}_{\mathrm{FA}}^{(\mathrm{m}), \exp }, u\left(\tilde{y}_{\mathrm{FA}}^{(\mathrm{m}), \exp }\right)=0.03 \tilde{y}_{\mathrm{FA}}^{(\mathrm{m}), \exp }, u\left(\tilde{x}_{\mathrm{BYD}}^{(\mathrm{m}) \exp }\right)=0.02 \tilde{x}_{\mathrm{BYD}}^{(\mathrm{m}), \exp }$.

b Measurement below detection limit of $0.0010 \mathrm{~g} \mathrm{~g}^{-1}$.

high $(19.2 \%)$ compared to the one of formaldehyde. On the other hand, regarding mole fractions, the highest experimental fraction of butynediol in the vapor phase is $6.210^{-4} \mathrm{~mol} \mathrm{~mol}^{-1}$ which has a negligible contribution to the total pressure. The deviations in the formaldehyde mass fraction and the pressure reported here are not higher than the deviations which were observed for the system formaldehyde + water [15]. Thus, changing any parameters of the model was not considered in the present work. Fig. 2 shows the results of two selected experiments at $393 \mathrm{~K}$ to illustrate the influence of butynediol in the liquid phase on the formaldehyde mass fraction in the vapor phase.

Squares represent the composition of the liquid phase. They are connected to the composition of the corresponding vapor phase (circles) via tie-lines. The overall mass fraction of formaldehyde in the liquid phase is approximately the same in both experiments. However, the butynediol fraction differs significantly. Formaldehyde reacts with both water and butynediol to form oligomers. The more butynediol is in the solution the more of the formaldeyhde is bound to butynediol. The resulting poly(oxymethylene) hemiformals have a negligible vapor pressure due to their large molecule

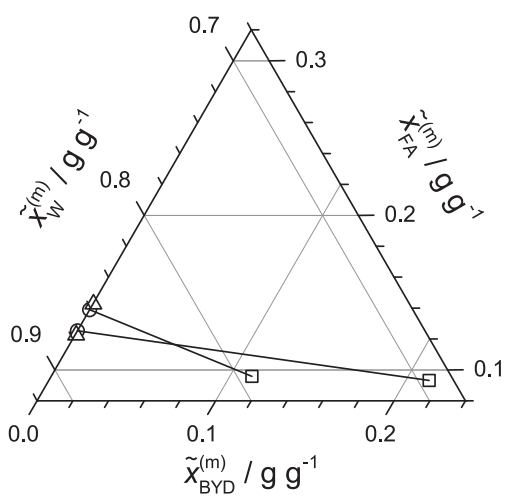

Fig. 2. Vapor-liquid equilibrium in the system formaldehyde + water + butynediol at $393 \mathrm{~K}$. ( $\square$ ) liquid phase composition, ( $(0)$ experimental vapor phase composition, $(\triangle)$ predicted vapor phase composition, (- $)$ tie line. size. Thus, formaldehyde is rather trapped in the liquid phase. Details on the distribution of formaldehyde between oligomers of water and butynediol, respectively, is given in detail by our earlier work [1] and thus not repeated here.

\section{Residue curve maps}

\subsection{Introduction}

For the illustration of the vapor-liquid behavior in the studied system, residue curves were calculated at constant pressure. The residue curves are the trajectories of the liquid phase composition obtained upon evaporating a liquid mixture slowly in an open still. They are closely related to distillation lines and can be used as an approximation for feasibility studies of distillation processes [23]. Mathematically, a differential-algebraic problem has to be solved which is described by the Rayleigh Equation [24]. In the case of a reactive distillation the equation can be formulated with overall mole fractions [25] according to

$\frac{\mathrm{d} \tilde{x}_{i}}{\mathrm{~d} \tau}=\tilde{x}_{i}-\tilde{y}_{i} \quad i=\mathrm{FA}, \mathrm{W}$

where $\tau$ can be considered as a dimensionless time. In the overall ternary system formaldehyde + water + butynediol the residue curves are then described by solving the following expression starting at an arbitrary overall composition:

$\frac{\mathrm{d} \tilde{x}_{\mathrm{FA}}}{\mathrm{d} \tilde{x}_{\mathrm{W}}}=\frac{\tilde{x}_{\mathrm{FA}}-\tilde{y}_{\mathrm{FA}}}{\tilde{x}_{\mathrm{W}}-\tilde{y}_{\mathrm{W}}}$

\subsection{Results and discussion}

The residue curve maps for the system formaldehyde + water + butynediol at $100 \mathrm{kPa}$ and $400 \mathrm{kPa}$ are shown in Fig. 3.

There are two azeotropic points in the binary system formaldehyde + water. The one next to pure formaldehyde is an 

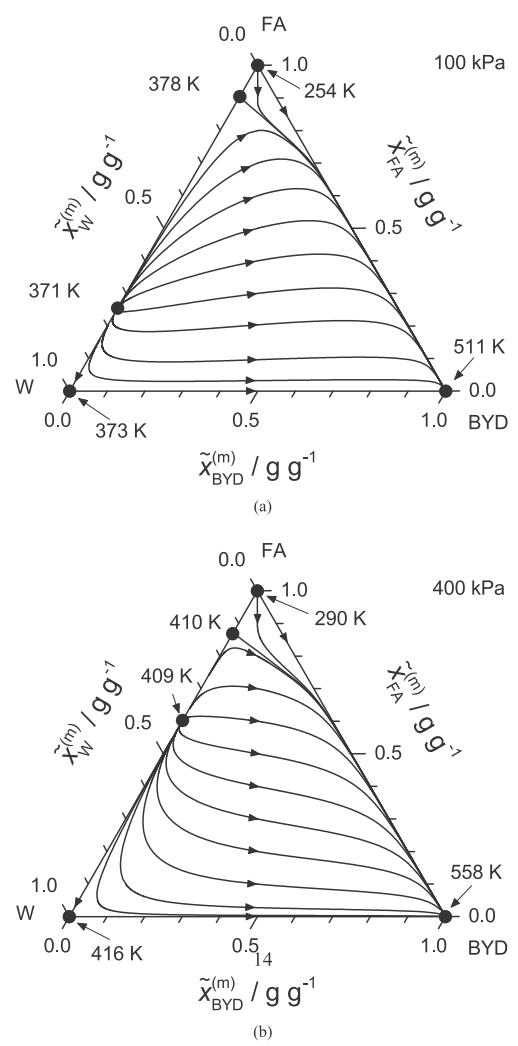

Fig. 3. Residue curve maps for the system formaldehyde + water + butynediol. (a) $100 \mathrm{kPa}$, (b) $400 \mathrm{kPa}$. (•) singular point.

artifact of the model since at this overall composition formaldehyde is present in very long poly(oxymethylene) glycol chains which crystallize at the given conditions. Neither the formation of a solid phase nor the formation of oligomers with $n>10$ is considered by the model. In practice the azeotrope replaces pure monomeric formaldehyde in the diagram.

All residue curves start in the other formaldehyde + water azeotrope (unstable node, global low boiler) and end in pure butynediol (stable node, global high boiler). Pure water and the second binary azeotrope are saddles in the diagram. Following the residue curves at $100 \mathrm{kPa}$ starting from a point near the global highboiling formaldehyde + water azeotrope but at lower formaldehyde concentration, formaldehyde is depleted initially. Coming to higher butynediol concentrations, formaldehyde is however enriched again because of the strong formaldehyde binding ability of butynediol [1], cf. also the discussion along Fig. 2.

At $400 \mathrm{kPa}$, and thus higher temperatures, the global highboiling azeotrope is located at a higher formaldehyde concentration since generally the oligomer chains in the liquid become shorter with rising temperature. Thus, following again residue curves below the unstable azeotrope, the depletion of formaldehyde is even stronger. Following the same argument, formaldehyde is also weaker bound in the poly(oxymethylene) hemiformals with butynediol.

\section{Conclusion}

The vapor-liquid equilibrium in reactive mixtures containing formaldehyde, water, and butynediol was investigated to validate a predictive physico-chemical model of the chemical equilibrium which has recently been published [1]. The experiments and the model predictions are in very good agreement, hence no fitting of parameters was necessary.

The distillation behavior of the studied mixtures was shown using residue curve maps. It can be concluded that the depletion of formaldehyde from the liquid phase becomes more difficult at increasing butynediol concentrations as butynediol bounds formaldehyde in oligomers. Higher pressures favor formaldehyde depletion as the oligomer chains become shorter and as a consequence formaldehyde becomes more volatile.

\section{Acknowledgments}

We gratefully acknowledge financial support of this work by BASF SE, Ludwigshafen, Germany. We thank Jens Weiguny, BASF SE, for fruitful discussions.

\section{Notation}

$\begin{array}{ll}\text { BYD } & \text { 2-butyne-1,4-diol } \\ \text { FA } & \text { formaldehyde } \\ K & \text { chemical equilibrium constant } \\ \text { MG } & \text { methylene glycol } \\ p & \text { pressure } \\ p_{i}^{\text {s }} & \text { vapor pressure of component } i \\ \text { W } & \text { water } \\ x_{i} & \text { true mole fraction of component } i \text { in the liquid phase } \\ \tilde{x}_{i} & \text { overall mole fraction of component } i \text { in the liquid phase } \\ x_{i}^{(\mathrm{m})} & \text { true mass fraction of component } i \text { in the liquid phase } \\ \tilde{x}_{i}^{(\mathrm{m})} & \text { overall mass fraction of component } i \text { in the liquid phase } \\ y_{i} & \text { true mole fraction of component } i \text { in the vapor phase } \\ \tilde{y}_{i} & \text { overall mole fraction of component } i \text { in the vapor phase } \\ y_{i}^{(\mathrm{m})} & \text { true mass fraction of component } i \text { in the vapor phase } \\ \tilde{y}_{i}^{(\mathrm{m})} & \text { overall mass fraction of component } i \text { in the vapor phase } \\ \gamma_{i} & \text { acitivity coefficient of component } i \\ \tau & \text { dimensionless time }\end{array}$

\section{References}

[1] J. Berje, J. Baldamus, J. Burger, H. Hasse, NMR spectroscopic study of chemical equilibria in solutions of formaldehyde, water, and butynediol, AIChE J. 63 (2017) 4442-4450.

[2] W. Reppe, Äthinylierung III, Justus Liebigs Ann. Chem. 596 (1) (1955) 25-38.

[3] W. Reppe, Chemie und Technik der Acetylen-Druck-Reaktionen, Chem. Ing. Tech. 22 (17) (1950) 361-373.

[4] W. Reppe, Chemie und Technik der Acetylen-Druck-Reaktionen (IV. Teil), Chem. Ing. Tech. 22 (23-24) (1950) 527-539.

[5] J.F. Walker, Formaldehyde, second ed., ACS Monograph Series, Reinhold, New York, 1953.

[6] G. Maurer, Vapor-liquid equilibrium of formaldehyde- and water-containing multicomponent mixtures, AIChE J. 32 (6) (1986) 932-948.

[7] H. Hasse, Dampf-Flüssigkeits-Gleichgewichte, Enthalpien und Reaktionskinetik in formaldehydhaltigen Mischungen, Ph.D. thesis, University of Kaiserslautern, Kaiserslautern, Germany, 1990.

[8] H. Hasse, I. Hahnenstein, G. Maurer, Revised vapor-liquid equilibrium model for multicomponent formaldehyde mixtures, AIChE J. 36 (12) (1990) 1807-1814.

[9] S. Brandani, V. Brandani, G. Di Giacomo, The system formaldehyde-watermethanol: thermodynamics of solvated and associated solutions, Ind. Eng. Chem. Res. 31 (7) (1992) 1792-1798.

[10] S. Brandani, V. Brandani, I. Tarquini, Vapor-liquid equilibrium of formaldehyde mixtures containing methanol, Ind. Eng. Chem. Res. 37 (8) (1998) 3485-3489.

[11] M. Albert, I. Hahnenstein, H. Hasse, G. Maurer, Vapor-liquid equilibrium of formaldehyde mixtures: new data and model revision, AIChE J. 42 (6) (1996) $1741-1752$.

[12] M. Albert, B.C. García, C. Kreiter, G. Maurer, Vapor-liquid and chemical equilibria of formaldehyde-water mixtures, AIChE J. 45 (9) (1999) 2024-2033.

[13] M. Albert, B. Coto Garca, C. Kuhnert, R. Peschla, G. Maurer, Vapor-liquid equilibrium of aqueous solutions of formaldehyde and methanol, AIChE J. 46 (8) (2000) 1676-1687.

[14] M. Albert, I. Hahnenstein, H. Hasse, G. Maurer, Vapor-liquid and liquid-liquid equilibria in binary and ternary mixtures of water, methanol, and methylal, J. Chem. Eng. Data 46 (4) (2001) 897-903. 
[15] C. Kuhnert, Dampf-Flüssigkeits-Gleichgewichte in Mehrkomponentigen Formaldehydhaltigen Systemen, Ph.D. thesis, University of Kaiserslautern, Kaiserslautern, Germany, 2003.

[16] M. Ott, Reaktionskinetik und Destillation formaldehydhaltiger Mischungen, Ph.D. thesis, University of Kaiserslautern, Kaiserslautern, Germany, 2004.

[17] M. Ott, H. Schoenmakers, H. Hasse, Distillation of formaldehyde containing mixtures: laboratory experiments, equilibrium stage modeling and simulation, Chem. Eng. Process 44 (6) (2005) 687-694.

[18] M. Albert, H. Hasse, C. Kuhnert, G. Maurer, New experimental results for the vapor-liquid equilibrium of the binary system (trioxane plus water) and the ternary system (formaldehyde plus trioxane plus water), J. Chem. Eng. Data 50 (4) (2005) 1218-1223.

[19] C. Kuhnert, M. Albert, S. Breyer, I. Hahnenstein, H. Hasse, G. Maurer, Phase equilibrium in formaldehyde containing multicomponent mixtures: experimental results for fluid phase equilibria of (formaldehyde + (water or methanol) + methylal)) and (formaldehyde + water + methanol + methylal) and comparison with predictions, Ind. Eng. Chem. Res. 45 (14) (2006)
5155-5164.

[20] M. Detcheberry, P. Destrac, X.-M. Meyer, J-S. Condoret, Phase equilibria of aqueous solutions of formaldehyde and methanol: improved approach using UNIQUAC coupled to chemical equilibria, Fluid Phase Equilib. 392 (2015) 84-94.

[21] Berufsgenossenschaft Rohstoffe und chemische Industrie (BG RCI), Datenblatt: 2-Butin-1,4-diol, October 2016. www.gischem.de.

[22] E. Pyatnitsyna, M. El'chaninov, A. Savost'yanov, Procedures for recovery of crystalline 2-Butyne-1,4-diol from industrial aqueous solutions and for its purification, Russ. J. Appl. Chem. 82 (8) (2009) 1428-1430.

[23] S. Widagdo, W.D. Seider, Journal review. azeotropic distillation, AIChE J. 42 (1) (1996) 96-130.

[24] J. Gmehling, B. Kolbe, M. Kleiber, J. Rarey, Chemical Thermodynamics for Process Simulation, first ed., WILEY-VCH, Weinheim, 2012.

[25] S. Ung, M.F. Doherty, Calculation of residue curve maps for mixtures with multiple equilibrium chemical reactions, Ind. Eng. Chem. Res. 34 (10) (1995) 3195-3202. 